\title{
Single nucleotide polymorphisms in the neuropeptide Y2 receptor (NPY2R) gene and association with severe obesity in French white subjects
}

\author{
A. Siddiq • M. Gueorguiev • C. Samson • S. Hercberg • \\ B. Heude • C. Levy-Marchal • B. Jouret • J. Weill • \\ D. Meyre $\cdot$ A. Walley $\cdot$ P. Froguel
}

Received: 19 July 2006 / Accepted: 20 October 2006 / Published online: 18 January 2007

(C) Springer-Verlag 2007

\begin{abstract}
Electronic supplementary material Supplementary material is available in the online version of this article at http://dx.doi.org/ $10.1007 / \mathrm{s} 00125-006-0555-2$ and is accessible to authorised users.
\end{abstract}

\author{
A. Siddiq $\cdot$ A. Walley $\cdot$ P. Froguel $(\bowtie)$ \\ Section of Genomic Medicine, \\ Imperial College London, Hammersmith Hospital, \\ Du Cane Road, \\ London W12 0NN, UK \\ e-mail: p.froguel@imperial.ac.uk \\ M. Gueorguiev \\ Bart's and the London Genome Centre, \\ Queen Mary's School of Medicine, \\ London, UK \\ C. Samson $\cdot$ D. Meyre $\cdot$ P. Froguel \\ Centre National de la Recherche Scientifique, UMR 8090, \\ Pasteur Institute, \\ Lille, France \\ S. Hercberg \\ U557 INSERM and Unite de Surveillance et d'Epidemiologie \\ Nutritionnelle, InVS/CNAM, Institut Scientifique et Technique \\ de la Nutrition et de l'Alimentation/CNAM, \\ Paris, France \\ B. Heude \\ INSERM, U258-IFR69, Paris South Faculty of Medicine, \\ Villejuif, France \\ C. Levy-Marchal \\ INSERM U457, Robert Debre Hospital, \\ Paris, France \\ B. Jouret \\ INSERM U563, Children's Hospital, \\ Toulouse, France \\ J. Weill \\ Paediatric Endocrine Unit, Jeanne de Flandre Hospital, \\ Lille, France
}

\begin{abstract}
Aims/hypothesis Genetic variants of genes for peptide YY $(P Y Y)$, neuropeptide Y2 receptor $(N P Y 2 R)$ and pancreatic polypeptide $(P P Y)$ were investigated for association with severe obesity.

Subjects and methods The initial screening of the genes for variants was performed by sequencing in a group of severely obese subjects $(n=161)$. Case-control analysis of the common variants was then carried out in 557 severely obese adults, 515 severely obese children and 1,163 nonobese/non-diabetic control subjects. Rare variants were genotyped in 700 obese children and the non-obese/nondiabetic control subjects $(n=1,163)$.

Results Significant association was found for a $5^{\prime}$ variant (rs6857715) in the NPY2R gene with both severe adult obesity $(p=0.002)$ and childhood obesity $(p=0.02)$. This significant association was further supported by a pooled allelic analysis of all obese cases (adults and children, $n=928)$ vs the control subjects $(n=938)(p=0.0004$, odds ratio $=1.3,95 \%$ CI $1.1-1.5$ ). Quantitative trait analysis of BMI and WHR was performed and significant association was observed for SNP rs1047214 in NPY2R with an increase in WHR in the severely obese children (codominant model $p=0.005$, recessive model $p=0.001$ ). Association was also observed for an intron 3 variant (rs162430) in the PYY gene with childhood obesity $(p=0.04)$. No significant associations were observed for $P P Y$ variants. Only one rare variant in the $N P Y 2 R$ gene (C-5641T) was not found in lean individuals and this was found to co-segregate with obesity in one family.

Conclusions/interpretation These results provide evidence of association for $N P Y 2 R$ and $P Y Y$ gene variants with obesity and none for $P P Y$ variants. A rare variant of the $N P Y 2 R$ gene showed evidence of co-segregation with
\end{abstract}


obesity and its contribution to obesity should be investigated further.

Keywords Appetite regulation · French white subjects · Neuropeptide Y2 receptor · Obesity · Pancreatic polypeptide . Peptide YY · Single nucleotide polymorphisms

$\begin{array}{ll}\text { Abbreviations } \\ \text { LD } & \text { linkage disequilibrium } \\ \text { NPY } & \text { neuropeptide Y } \\ \text { NPY2R } & \text { neuropeptide Y2 receptor } \\ \text { OR } & \text { odds ratio } \\ \text { PPY } & \text { pancreatic polypeptide } \\ \text { PYY } & \text { peptide YY } \\ \text { SNP } & \text { single nucleotide polymorphism } \\ \text { ZBMI } & z \text { score of BMI }\end{array}$

\section{Introduction}

Many neuropeptides affecting food intake and/or energy expenditure have been described to date [1-4]. The recent identification of hunger and satiety peptides, as well as their receptors, has increased the interest in appetite regulation, particularly for the treatment of eating disorders, from anorexia to overeating and obesity [2].

Peptide YY (PYY) is a member of a gene family that also includes neuropeptide Y (NPY) and pancreatic polypeptide (PPY). The three peptides have differential patterns of production: PYY is released by the L-cells of the gastrointestinal tract in response to food intake $[5,6]$ and inhibits both pancreatic and gastric secretion. NPY has been localised to both brain and peripheral neurons and PPY is localised to the pancreas [7].

The human $P Y Y$ gene was first cloned by Hort et al. [8] and, based on the gene structures of $P Y Y, N P Y$ and $P P Y$, it was concluded that $P Y Y$ and $N P Y$ are the result of a gene duplication event and a further tandem duplication event gave rise to the $P P Y$ gene.

Two forms of PYY are found in the gut and circulation: $\mathrm{PYY}_{1-36}$ and $\mathrm{PYY}_{3-36}$ [9-11]. Batterham et al. provided the first evidence that $\mathrm{PYY}_{3-36}$ is a mediator of postprandial satiety in rodents [6] and humans [12] through actions at the arcuate nucleus via NPY2 receptor (NPY2R). Since then many studies have established the role of PYY in decreasing food intake in both animals [13-18] and humans [19-21]. However, contradictory evidence has also been presented, suggesting that PYY $\mathrm{PY}_{36}$ does not decrease food intake in rodents, further questioning its role as a potential anti-obesity drug target $[22,23]$.

The NPY2R is a pre-synaptic inhibitory receptor that is abundantly expressed in the arcuate nucleus [24]. It has been established that mice lacking the NPY2R gene have an increased body weight and food intake [25].

There is suggestive evidence of linkage of abdominal subcutaneous fat to the chromosomal region 17q21.1 (LOD= 2.24 ), which is in close proximity to where both the $P Y Y$ and PPY genes are located [26].

Plasma levels of PPY have also been found to be decreased in human morbid obesity $[27,28]$ and increased in cases of anorexia nervosa [27-29]. PPY is reported to inhibit food intake and stimulate energy expenditure following its peripheral administration [30]. It has been shown that children with Prader-Willi syndrome have decreased secretion of PPY [31] and that peripheral administration of PPY leads to a decrease in food intake in rodents [32]. PPY administration in humans also leads to a sustained decrease in both appetite and food intake [33]. However, it has been demonstrated that low levels of PPY in obese children normalise after weight loss, suggesting that levels of PPY may reflect the overweight status rather than cause it [34]. These observations indicate that PPY may be involved in the regulation of energy balance and possibly the aetiology of obesity.

Three previous published studies have focused on both the PYY and NPY2R genes [35-37], while two further studies have focused on $P Y Y$ variants alone in association with type 2 diabetes [38, 39] and overweight [39]. In British white subjects two common single nucleotide polymorphisms (SNPs) in exon $2(585 \mathrm{~T}>\mathrm{C}$ and $936 \mathrm{~T}>\mathrm{C})$ of the NPY2R gene were in strong linkage disequilibrium (LD). It was found that men homozygous for the rarer variant had significantly lower BMI $\left(\mathrm{kg} / \mathrm{m}^{2}\right)(p=0.017)$ and WHR $(p=0.013)$ and also higher NEFA levels $(p=0.01)$ [36]. Variations in $P Y Y$ and $N P Y 2 R$ gene were also found to be associated with obesity in male Pima Indians. It was found that two variants in the $5^{\prime}$ flanking region of the $P Y Y$ gene and an intron 3 variant (rs162430) were associated with severe obesity $(p=0.001)$. Similar to the British result there was a significant association for the two common SNPs in exon 2 of the NPY2R gene with severe obesity $(p=0.002)$ [35]. The study in the Swedish men concentrated on the previously associated $N P Y 2 R$ gene variant $585 \mathrm{~T}>\mathrm{C}$ (rs1047214) and the PYY gene Arg72Thr variant (rs1058046). No association was found for the PYY gene variant; however, the common TT genotype of the 585T $>\mathrm{C}$ variant was found to be protective against obesity in the Swedish men $(p=0.002)$ [37]. Less is known about rare variants in these appetite-regulating genes and their role in predisposition to obesity. So far only one study has shown an association between a rare variant $(\mathrm{Q} 62 \mathrm{P})$ in the $P Y Y$ gene and susceptibility to obesity [40]. This study also reported that a common variant in the $P Y Y$ gene (R72T) was associated with obesity $(p=0.02)$ [40] and the same variant (R72T) has also been associated with overweight in a Danish study group [39]. 
In our study, a total of 16 common SNPs (minor allele frequency $\geq 0.05$ ) were analysed: three SNPs in $P Y Y$, two SNPs in $P P Y$, seven SNPs in the NPY2R gene and a further four SNPs in the $10-\mathrm{kb}$ region between $P Y Y$ and $P P Y$. These were examined for association with severe obesity in 557 French white obese adults and 515 obese children with a total of 1,163 non-obese control subjects. A total of nine rare variants were also examined in 700 obese children (from 479 families) and the non-obese/non-diabetic control subjects $(n=1,163)$. If the rare variant was not present in the control subjects and only in the obese children then it was subsequently followed up in the family of the obese children to test for co-segregation with obesity.

\section{Subjects and methods}

Informed written consent was obtained from all the subjects before participation. The Ethical Committee of Hotel Dieu in Paris and CHRU in Lille approved the genetic study.

Subjects Initial SNP screening was performed in 105 morbidly obese $\left(B M I \geq 40 \mathrm{~kg} / \mathrm{m}^{2}\right)$ adults, 56 morbidly obese children with $z$ score of BMI $(Z B M I) \geq 2$ and an early onset of obesity. The average age of onset of childhood obesity was $4.0 \pm 2.7$ years and the maximum age of onset was 18 years. The 97th percentile was used as the threshold of obesity for the French children in accordance with the European Childhood Obesity Group recommendations [41]. For the case-control study, 557 (131 males, 426 females) unrelated adult morbidly obese subjects were used and 515 (226 males, 277 females, sex data missing for 12 subjects) unrelated obese children were used (age $<18$ years with a BMI $>97$ th percentile for age and sex). The controls used for the study were all nonobese and non-diabetic $(n=1,163)$; further details are provided in the Electronic Supplementary Material (ESM).

Fasting blood glucose was used to define NGT with $\mathrm{Gly}_{0}<5.6 \mathrm{mmol} / \mathrm{l}$ used to define the non-diabetic state for all control subjects. A total of 700 obese children (341 males, 359 females) from 479 distinct pedigrees were analysed for the co-segregation analysis of the rare variant; these children had a BMI $>97$ th percentile $(Z B M I=3.98 \pm$ $2.57 \mathrm{~kg} / \mathrm{m}^{2}$, age at examination $=11.36 \pm 3.15$ years, age of onset of obesity $=3.91 \pm 2.57$ years).

Phenotypes Phenotypes were measured as previously described [42]; further details are available in the ESM.

$P C R$ and sequencing Primers were designed for all three genes using the Primer 3 program [43] to include $1 \mathrm{~kb}$ upstream from the first exon and $1 \mathrm{~kb}$ downstream from the last exon covering the entire gene. All primer sequences are available on request. There were a total of eight primer pairs designed for $P Y Y, 13$ for NPY2R and 10 for PPY. PCR and sequencing was carried out as previously [44].

Genotyping Genotyping of the majority of SNPs was performed using the Sequenom MassARRAY system [45] as previously [44]. Two NPY2R SNPs (rs17376798, rs6857530) were genotyped using the fluorescent $5^{\prime}$ nuclease Taqman method on an ABI PRISM 7900 HT Sequence Detection System. The conditions for Taqman reaction were as follows: $50^{\circ} \mathrm{C}$ for $2 \mathrm{~min}, 95^{\circ} \mathrm{C}$ for $10 \mathrm{~min}, 95^{\circ} \mathrm{C}$ for $15 \mathrm{~s}$, $60^{\circ} \mathrm{C}$ for $1 \mathrm{~min}$; for 50 cycles. Taqman MGB probes were from Applied Biosystems, Foster City, CA, USA.

Statistical analysis None of the SNPs significantly deviated from Hardy-Weinberg equilibrium $(p>0.05)$. All the SNPs had a genotyping success rate of above $75 \%$, with an average rate of $88 \%$ overall. Furthermore, we also genotyped 100 severely obese subjects by sequencing and this showed 99\% concordance between the results for Sequenom and sequencing. LD was estimated using the expectation-maximisation algorithm implemented in GOLD [46]. Statistical analyses of SNPs (chi-squared test and quantitative trait analysis) were performed using SPSS software (version 11.0, SPSS, Inc., Chicago, IL, USA). Linear regression was used to assess the effects of the genetic variable on a given phenotype. Differences between the genotypes in a co-dominant model were tested with one-way ANOVA for all the quantitative traits studied. However, if any genotype groups had a sample size below 30, the Kruskal-Wallis test was used. Differences between two groups of genotypes were tested using a parametric $t$ test. Haplotype frequencies were determined and compared between the groups of cases and controls using UNPHASED [47]. In consideration of the number of statistical tests carried out, a simple correction for multiple testing of SNPs in LD with each other was carried out using the method proposed by Nyholt [48].

\section{Results}

Sequencing The locations of all the SNPs are shown in Fig. 1.

PYY gene Seven variants were detected by sequencing in the PYY gene (Table 1). Four of these variants were common, i.e. had a minor allele frequency of $\geq 0.05$ and three were rare. Initial LD was calculated between these SNPs and rs2070592 in the $5^{\prime}$ UTR and rs 1058046 in exon 3 in high LD $\left(r^{2}=0.955, D^{\prime}=0.985, p<0.001\right)$ (data not shown), so only the latter was selected for genotyping. 


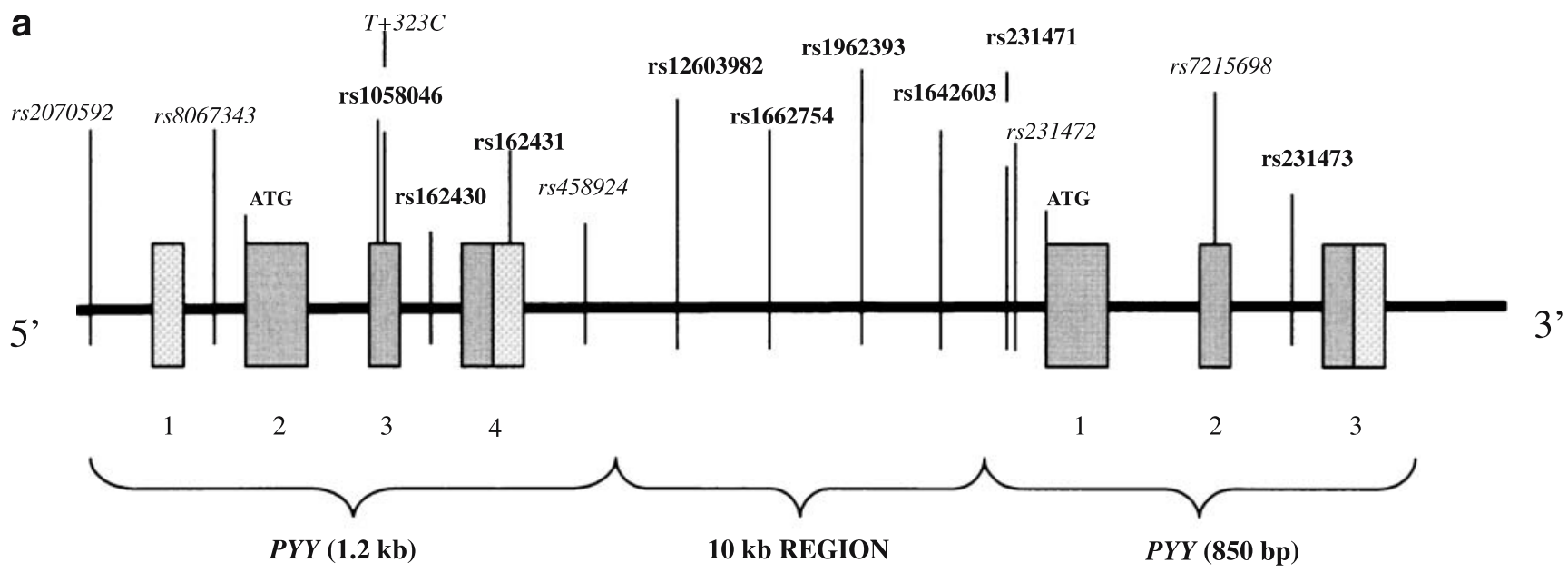

b

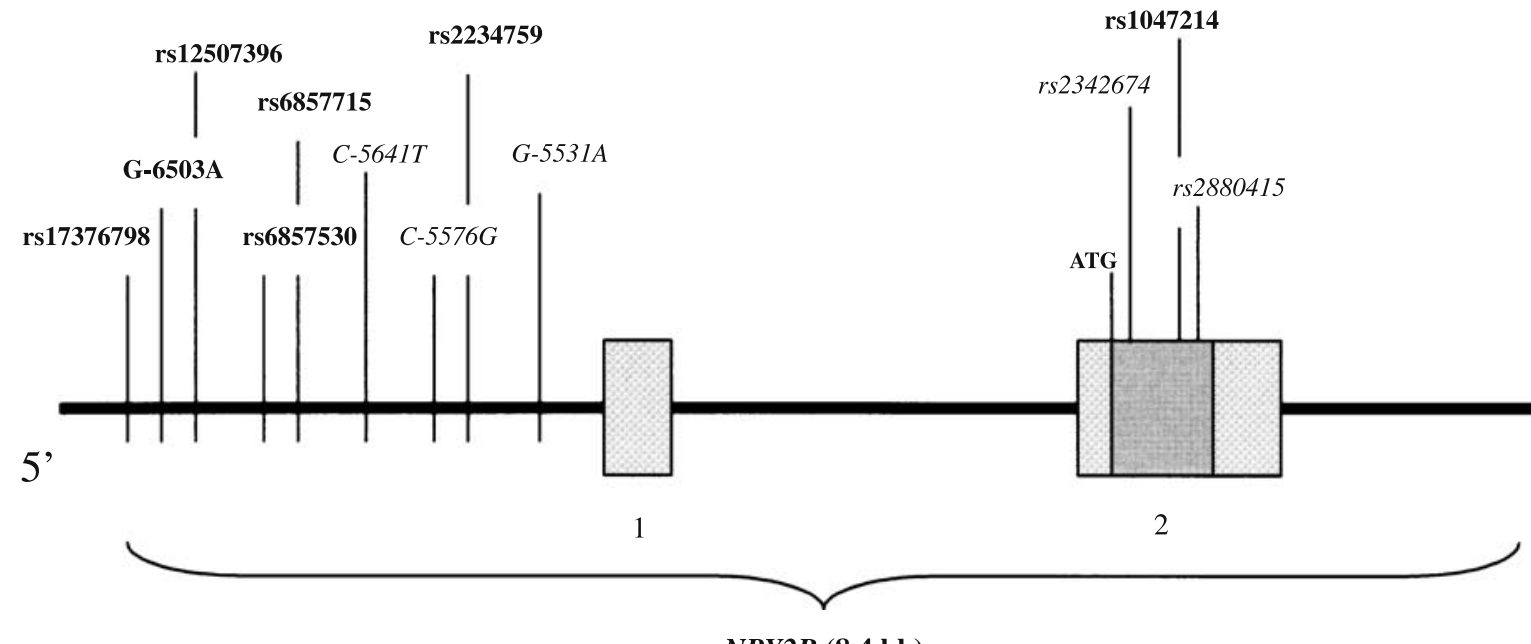

NPY2R (8.4 kb)

Fig. 1 Schematic diagram of $P Y Y, P P Y$ and $N P Y 2 R$ genes showing SNPs identified by sequencing. a chromosome 17q21; b chromosome 4q31. All the SNPs shown were identified by sequence analysis, exons are shown as boxes; filled box regions represent the coding region; patterned box regions represent the non-coding region; numbers represent the exons. SNPS in italics represent the rare variant (frequency<0.05) or those in LD with other variants
PPY gene Four variants were identified (Table 1): two common and two rare. Figure 1 shows the location for all $P P Y$ variants.

NPY2R gene A total of 12 variants were detected by sequencing in the $N P Y 2 R$ gene (Table 1). Eight of the variants were common and four rare. High LD was observed between the two common variants in exon 2 $\left(r^{2}=0.942, D^{\prime}=0.985, p<0.001\right)$ so only one (rs1047214) was selected for genotyping.

Genotyping The SNPs selected for genotyping in the obese cases and controls are shown in Table 1. SNPs that were in high LD were not selected for further genotyping. Four additional SNPs were selected directly from dbSNP (http://www.ncbi.nlm.nih.gov/SNP/) within the $10-\mathrm{kb}$ region between the $P Y Y$ and $P P Y$ genes. These were frequent (minor allele frequency $>0.38$ ) and on average $2 \mathrm{~kb}$ apart. Pairwise LD was calculated for all the common variants (frequency $>0.05$ ) for NPY2R SNPs at chromosome $4 \mathrm{q} 31$ and for $P Y Y$ and $P P Y$ SNPs at chromosome 17q21 region; the results are shown in Fig. $2 \mathrm{a}$ and $\mathrm{b}$. For a relative risk of 1.2 it is estimated that we have an $84 \%$ power to detect an association with severe obesity in our population using 1,163 controls and our combined 1,072 cases. The statistical power is reduced when analysing adult and child cases separately; however, for a slightly raised relative risk of 1.4 we still have $68 \%$ power to detect an association with severe obesity at $p<0.05$ [49].

PYY and PPY genes LD was calculated over the $\sim 12-\mathrm{kb}$ region containing both the $P Y Y$ and $P P Y$ genes. The 
Table 1 Sequencing results for $N P Y 2 R, P P Y$ and $P Y Y$ genes

\begin{tabular}{|c|c|c|c|c|c|}
\hline Gene & SNP & Variant & Amino acid change & Frequency & NCBI location (bp) \\
\hline \multirow[t]{12}{*}{$N P Y 2 R$} & rs 17376798 & $\mathrm{G} / \mathrm{C}$ & - & $0.92 / 0.08$ & 156486183 \\
\hline & G-6503A & $\mathrm{G} / \mathrm{A}$ & - & $0.70 / 0.30$ & 156486195 \\
\hline & rs12507396 & $\mathrm{A} / \mathrm{T}$ & - & $0.89 / 0.11$ & 156486649 \\
\hline & rs 6857530 & $\mathrm{~A} / \mathrm{G}$ & - & $0.60 / 0.40$ & 156486759 \\
\hline & rs6857715 & $\mathrm{C} / \mathrm{T}$ & - & $0.70 / 0.30$ & 156486787 \\
\hline & $C-5641 T$ & $\mathrm{C} / \mathrm{T}$ & - & $0.99 / 0.01$ & 156487056 \\
\hline & $C-5576 G$ & $\mathrm{C} / \mathrm{G}$ & - & $0.99 / 0.01$ & 156487121 \\
\hline & rs2234759 & $\mathrm{A} / \mathrm{G}$ & - & $0.79 / 0.19$ & 156487162 \\
\hline & $G-5531 A$ & $\mathrm{G} / \mathrm{A}$ & - & $0.97 / 0.03$ & 156487166 \\
\hline & $r s 2342674$ & $\mathrm{G} / \mathrm{A}$ & $\mathrm{L} 53 \mathrm{~L}$ & $0.99 / 0.01$ & 156492855 \\
\hline & rs 1047214 & $\mathrm{~T} / \mathrm{C}$ & I195I & $0.55 / 0.45$ & 156493281 \\
\hline & $r s 2880415$ & $\mathrm{~T} / \mathrm{C}$ & $\mathrm{I} 312 \mathrm{I}$ & $0.55 / 0.45$ & 156493632 \\
\hline \multirow[t]{4}{*}{$P P Y$} & rs231473 & $\mathrm{G} / \mathrm{A}$ & - & $0.54 / 0.46$ & 39373997 \\
\hline & $r s 7215698$ & $\mathrm{~T} / \mathrm{C}$ & E78G & $0.99 / 0.01$ & 39374067 \\
\hline & $r s 231472$ & $\mathrm{C} / \mathrm{G}$ & - & $0.99 / 0.01$ & 39374904 \\
\hline & rs231471 & $\mathrm{A} / \mathrm{G}$ & - & $0.53 / 0.47$ & 39375020 \\
\hline \multirow[t]{4}{*}{$10-\mathrm{kb}$ region } & rs1642603 & $\mathrm{C} / \mathrm{T}$ & - & $0.62 / 0.38$ & 39377233 \\
\hline & rs1962393 & $\mathrm{A} / \mathrm{G}$ & - & $0.56 / 0.44$ & 39379895 \\
\hline & rs1662754 & $\mathrm{A} / \mathrm{T}$ & - & $0.58 / 0.42$ & 39381051 \\
\hline & rs12603982 & $\mathrm{T} / \mathrm{C}$ & - & $0.57 / 0.43$ & 39382099 \\
\hline \multirow[t]{7}{*}{$P Y Y$} & rs458924 & $\mathrm{C} / \mathrm{T}$ & - & $0.99 / 0.01$ & 39385177 \\
\hline & rs162431 & $\mathrm{C} / \mathrm{A}$ & - & $0.95 / 0.05$ & 39385701 \\
\hline & rs162430 & $\mathrm{C} / \mathrm{T}$ & - & $0.91 / 0.09$ & 39385935 \\
\hline & $T 323 C$ & $\mathrm{~T} / \mathrm{C}$ & L73P & $0.99 / 0.01$ & 39386054 \\
\hline & rs1058046 & $\mathrm{G} / \mathrm{C}$ & $\mathrm{R} 72 \mathrm{~T}$ & $0.65 / 0.35$ & 39386057 \\
\hline & $r s 8067343$ & $\mathrm{G} / \mathrm{A}$ & - & $0.99 / 0.01$ & 39386726 \\
\hline & $r s 2070592$ & $\mathrm{~A} / \mathrm{G}$ & - & $0.65 / 0.35$ & 39386857 \\
\hline
\end{tabular}

The rare SNPs and those in LD with others are shown in italics. The following SNPs: G-6503A, C-5641T, C-5576G, G-5531A and T323C were not in dbSNP and these are numbered according to the ATG start site. SNPs in the 10-kb region between the $P Y Y$ and $P P Y$ genes were selected from the dbSNP; the frequencies shown are those that were found in the database for this region as it was not covered by sequence analysis $L$, leucine; $I$, isoleucine; $E$, glutamic acid; $G$, glycine; $T$, threonine; $R$, arginine

average $D^{\prime}$ across the region was 0.74 . Strong LD was observed between the $P P Y$ variants rs231471 and rs231473 $\left(D^{\prime}=0.99\right)$. Similarly, complete LD was observed for $P Y Y$ SNPs rs162431 and rs1058046 $\left(D^{\prime}=1\right)$.

We examined whether the $P Y Y$ and $P P Y$ SNPs were associated with obesity in both severely obese adults $\left(B M I \geq 40 \mathrm{~kg} / \mathrm{m}^{2}\right)$ and children (age $<18$ years with a BMI $>97$ th percentile for age and sex). It was observed that one $\mathrm{C} / \mathrm{T}$ variant in intron 3 (rs162430) of the PYY gene was associated with childhood obesity $(p=0.04)$, but this was not found to be associated with severe adult obesity $(p=0.84)$ (Table 2). The minor $\mathrm{T}$ allele associated with obesity, with a frequency of $13 \%$ in the child cases compared with $10 \%$ in the controls $(p=0.03$, odds ratio $[\mathrm{OR}]=1.32$ [95\% CI 1.04-1.67]) (Table 2).

NPY2R gene The average LD $\left(D^{\prime}\right)$ observed across the $N P Y 2 R$ gene was 0.80 . Strong LD was observed between the 5 ' flanking region SNPs compared with the exon 2 SNP (Fig. 2b). SNP G-6503A was in strong LD with rs6857530
$\left(D^{\prime}=0.99\right)$, rs6857715 with rs6857530 $\left(D^{\prime}=0.99\right)$ and rs12507396 with rs2234759 $\left(D^{\prime}=0.97\right)$.

One variant (rs6857715) in the NPY2R gene was found to be significantly associated with both severe adult obesity and childhood obesity $(p=0.002$ and $p=0.02)$. The minor $\mathrm{T}$ allele was significantly associated with severe obesity in adults $(\mathrm{OR}=1.4$ [95\% CI 1.1-1.6], $p=0.0005)$ and children $(\mathrm{OR}=1.2$ [95\% CI 1.0-1.4], $p=0.02)$ (Table 3). Pooling data from obese children and obese adults vs controls slightly increased the significance of association $(\mathrm{OR}=1.3$ [95\% CI 1.1-1.5], $p=0.0004)$.

Haplotype analysis was performed for the common variants using UNPHASED for all the obese cases and controls for both NPY2R and the PPY gene, and the $10-\mathrm{kb}$ region and $P Y Y$ gene separately. There was no association with obesity for haplotypes above a frequency of $5 \%$ for NPY $2 R$ or the PPY, $10-\mathrm{kb}$ region and PYY with obesity. Association with obesity was observed for haplotypes of low frequency $(<5 \%)$ but these may be artefacts of the haplotype prediction process (data not shown). 
a
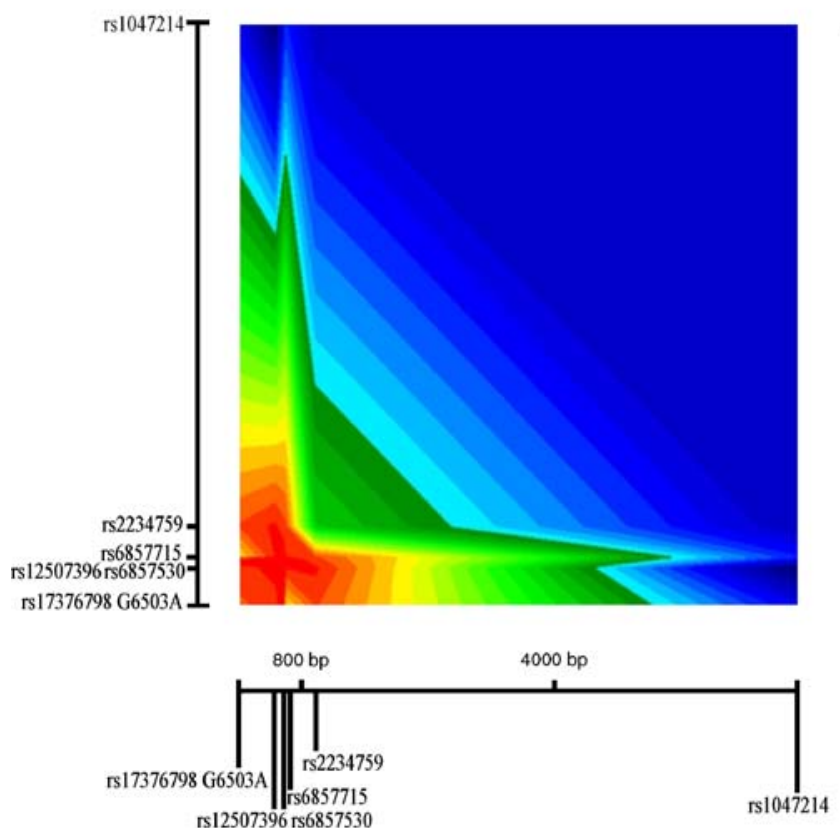

Fig. 2 Graphical representation of LD for $N P Y 2 R, P P Y$ and $P Y Y$ genes. a Pairwise LD measures $\left(\mathrm{D}^{\prime}\right)$ for common SNPs spanning the $N P Y 2 R$ gene on chromosome 4q31. b Pairwise LD measures $\left(D^{\prime}\right)$ for

Quantitative trait analysis Quantitative analysis of BMI and WHR was performed for all 16 common SNPs in three different groups: 557 severely obese adults, 662 severely obese children and 546 Supplementation en Vitamines et Minéraux Antioxidant study (Suvimax) subjects (largest set of controls). No association was found with BMI and WHR in the Suvimax control subjects for any of the tested SNPs $(p>0.05)$; similarly no association was found in the severely obese adults. However, a $\mathrm{T}$ to $\mathrm{C}$ variant in exon 2 (rs1047214) of the NPY2R gene was found to be significantly associated with an increase in WHR in severely obese children $(p=0.005)$, and this was stronger when analysed using a recessive model $(\mathrm{TT}+\mathrm{TC}$ : $\mathrm{WHR}=$ $0.92 \pm 0.08$ vs CC: $\mathrm{WHR}=0.95 \pm 0.09)(p=0.001)$. Further analysis by sex demonstrated that it was still associated with an increase in WHR in males $(p=0.01)$ and females $(p=0.05)$ (Table 4). Lastly, age of onset of obesity was also analysed as a quantitative trait in the obese children and no association was found with the studied common variants (data not shown).

Rare variants Eight out of the nine observed rare variants were present in non-obese controls $(n=1,163)$ and children (data not shown). One NPY2R gene rare variant (C-5641T) was not found in the non-obese control subjects $(n=1,163)$. The C-5641T variant was only observed in obese children b
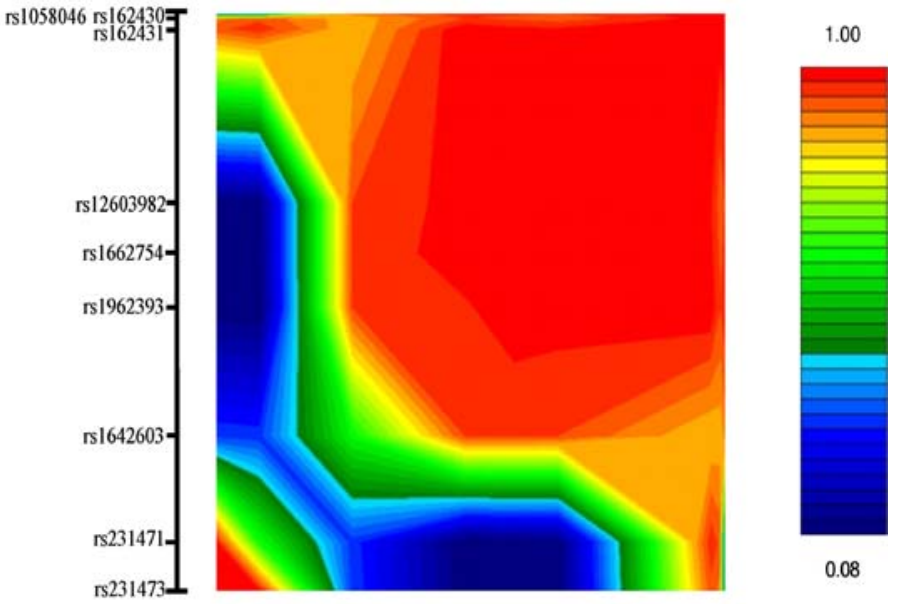

0.08

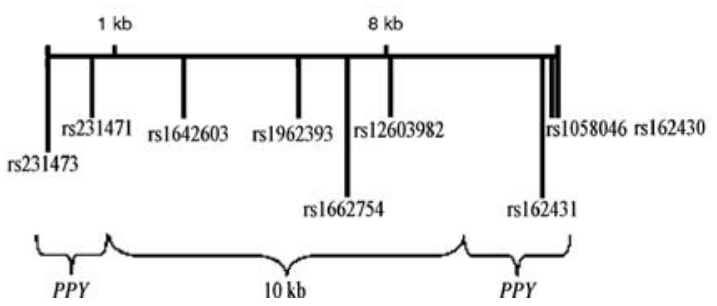

common SNPs spanning the $P P Y, 10-\mathrm{kb}$ region and $P Y Y$ gene on chromosome 17q21. All SNPs are positioned according to NCBI chromosome location

belonging to one family when a total of 700 obese children (from 479 families) were analysed (Fig. 3). Four subjects carrying the variant $\mathrm{T}$ allele were severely obese (the mother $\left[\mathrm{BMI}=47.46 \mathrm{~kg} / \mathrm{m}^{2}\right]$ and three offspring $[\mathrm{ZBMI}=$ 3.30, 2.40 and 2.91, respectively]), while the father and his mother carrying the $\mathrm{C}-5641 \mathrm{C}$ genotype were lean $(\mathrm{BMI}=$ 24.26 and $25.28 \mathrm{~kg} / \mathrm{m}^{2}$, respectively).

\section{Discussion}

Over the last few years much emphasis has been placed on the role of PYY, PPY and NPY2R in relation to obesity [6, $12,16,22,28,33]$ in both humans and animal models. From the literature it has been demonstrated that NPY2R is a crucial receptor in appetite regulation. NPY2R knock-outs have been shown to increase food intake, weight and adiposity [25]. Furthermore, in other mouse models, it has been observed that NPY2R regulates production of NPY, agouti-related peptide (AgRP), proopiomelanocortin (POMC) and cocaine and amphetamine regulated transcript (CART), and these changes are associated with functional changes in food intake [50]. Abbott et al. [51] have demonstrated that blockade of the NPY2R with a specific antagonist lowers the effect of endogenous and exogenous 
Table 2 Genotype distribution of common $P Y Y$ and $P P Y$ SNPs in obese adults and children

\begin{tabular}{|c|c|c|c|c|c|c|}
\hline & \multirow[t]{2}{*}{ Subjects } & \multicolumn{3}{|c|}{ Genotypes (\%) } & \multirow[t]{2}{*}{ Total } & \multirow[t]{2}{*}{$p$ value, all subjects } \\
\hline & & 11 & 12 & 22 & & \\
\hline \multirow[t]{3}{*}{ PYY_rs1058046 } & Control & $428(44.7)$ & $424(44.3)$ & $105(11.0)$ & 957 & \\
\hline & Adults & $207(42.9)$ & $215(44.6)$ & $60(12.4)$ & 482 & 0.66 \\
\hline & Children & $193(41.9)$ & $210(45.7)$ & $57(12.4)$ & 460 & 0.54 \\
\hline \multirow[t]{3}{*}{ PYY_rs162430 } & Control & $872(81.1)$ & $189(17.6)$ & $14(1.3)$ & 1075 & \\
\hline & Adults & $393(80.2)$ & $89(18.2)$ & $8(1.6)$ & 490 & 0.84 \\
\hline & Children & $349(75.5)$ & $107(23.2)$ & $6(1.3)$ & 462 & $0.04^{\mathrm{a}}$ \\
\hline \multirow[t]{3}{*}{ PYY_rs162431 } & Control & $979(91.2)$ & $90(8.4)$ & $4(0.4)$ & 1073 & \\
\hline & Adults & $466(90.3)$ & $47(9.1)$ & $3(0.6)$ & 516 & 0.75 \\
\hline & Children & $411(90.3)$ & $43(9.5)$ & $1(0.22)$ & 455 & 0.72 \\
\hline \multirow[t]{3}{*}{ rs 12603982} & Control & $265(30.1)$ & $465(57.8)$ & $151(17.1)$ & 881 & \\
\hline & Adults & $151(29.3)$ & $262(50.7)$ & $103(20)$ & 516 & 0.42 \\
\hline & Children & $147(31.7)$ & $230(49.6)$ & $87(18.8)$ & 464 & 0.52 \\
\hline \multirow[t]{3}{*}{ rs 1662754} & Control & $273(31.8)$ & $429(49.9)$ & $157(18.3)$ & 859 & \\
\hline & Adults & $146(32.7)$ & $214(47.9)$ & $87(19.5)$ & 447 & 0.76 \\
\hline & Children & $117(32.1)$ & $179(49.2)$ & $68(18.7)$ & 364 & 0.97 \\
\hline \multirow[t]{3}{*}{ rs1962393 } & Control & $314(30.6)$ & $522(50.9)$ & $190(18.5)$ & 1026 & \\
\hline & Adults & $142(28.2)$ & $262(52)$ & $100(19.8)$ & 504 & 0.58 \\
\hline & Children & $143(31)$ & $233(51)$ & 85 (18) & 461 & 0.98 \\
\hline \multirow[t]{3}{*}{ rs1642603 } & Control & 365 (37.9) & 471 (48.9) & $126(13.1)$ & 962 & \\
\hline & Adults & $204(40.4)$ & $235(46.5)$ & $66(13.1)$ & 505 & 0.63 \\
\hline & Children & $183(40.5)$ & $200(44.2)$ & $69(15.3)$ & 452 & 0.22 \\
\hline \multirow[t]{3}{*}{ PPY_rs231471 } & Control & $298(30.9)$ & 443 (45.9) & $224(23.2)$ & 965 & \\
\hline & Adults & $144(29.6)$ & $233(47.8)$ & $110(22.6)$ & 487 & 0.78 \\
\hline & Children & $125(27.8)$ & $225(50)$ & $100(22.2)$ & 450 & 0.33 \\
\hline \multirow{3}{*}{ PPY_rs231473 } & Control & $318(30.8)$ & $487(47.1)$ & $228(22.1)$ & 1033 & \\
\hline & Adults & $147(29.3)$ & $243(48.5)$ & $111(22.2)$ & 501 & 0.83 \\
\hline & Children & $128(27.4)$ & 229 (48.9) & $111(23.7)$ & 468 & 0.39 \\
\hline
\end{tabular}

Analysis of the SNPs is based on a co-dominant model

${ }^{a}$ After taking multiple testing into account this result is no longer significant

For $P Y Y$ and $P P Y$ SNPs the experiment-wide significance threshold required to keep type I error rate at $5 \%$ is 0.007

Male and female (sex-separated) analysis can be found in the (ESM Tables 1 and 2, respectively)

$\mathrm{PYY}_{3-36}$ on food intake. This study supports that NPY2R plays an important role in post-prandial satiety. There has also been discussion regarding potential therapeutic manipulation based on development of Y2 agonists, exogenous administration of $\mathrm{PYY}_{3-36}$ or increased endogenous release from the gastrointestinal tract [52]. These physiological studies draw attention to the importance of both PYY and NPY2R with regard to appetite regulation.

An SNP (rs6857715) in the 5' flanking region of the $N P Y 2 R$ gene was significantly associated with severe obesity in both French white adults $(p=0.002)$ and children $(p=0.02)$. The variant $\mathrm{T}$ allele was associated with adult obesity $(\mathrm{OR}=1.4$ [95\% CI 1.1-1.6], $p=0.0005)$ and with childhood obesity ( $\mathrm{OR}=1.2$ [95\% CI 1.0-1.4], $p=0.02)$. It is also important to note that the association in severely obese adults remains significant even after correcting for multiple testing using the method of Nyholt [48]. When analysing each sex separately, the SNP rs6857715 was significantly associated with adult obesity in female $(p=0.003)$, but not in male $(p>0.05)$ subjects, possibly due to the greater number of female subjects (426) compared with men (131). In Pima Indians, the NPY2R SNP rs6857715 was associated with obesity [35], using a co-dominant model, but the results were non-significant $(p=0.067)$. However, using a recessive model it was found to be significantly associated with severe obesity $(p=0.02)$. These results are in agreement with ours, as using a recessive model we also demonstrate significant association with adult obesity $(p=0.006)$. However, from our results it was observed that the dominant model $(\mathrm{CC}$ vs $\mathrm{CT}+\mathrm{TT})$ for SNP rs6857715 was more significant for the obese children $(p=0.007)$, and this model was also found to be more significant in the obese adults $(p=0.004)$. This SNP was not studied in either the British white subjects [36] or the Swedish men [37].

Using the Vista Genome Browser (http://www.pipeline. lbl.gov/cgi-bin/gateway2?bg=hg17\&selector $=$ vista), the NPY2R gene region where the rs6857715 SNP is located 
Table 3 Genotype distribution of common NPY2R SNPs in obese adults and children

\begin{tabular}{|c|c|c|c|c|c|c|}
\hline & \multirow[t]{2}{*}{ Subjects } & \multicolumn{3}{|c|}{ Genotypes (\%) } & \multirow[t]{2}{*}{ Total } & \multirow[t]{2}{*}{$p$ value, all subjects } \\
\hline & & 11 & 12 & 22 & & \\
\hline \multirow[t]{3}{*}{ rs 17376798} & Control & $945(85.9)$ & $151(13.8)$ & $3(0.3)$ & 1,099 & \\
\hline & Adults & $446(85.3)$ & $71(13.6)$ & $6(1.1)$ & 523 & 0.09 \\
\hline & Children & $417(87.4)$ & $57(12)$ & $3(0.6)$ & 477 & 0.37 \\
\hline \multirow[t]{3}{*}{ G-6503A } & Control & $497(49.5)$ & 419 (41.7) & $89(8.8)$ & 1,005 & \\
\hline & Adults & $227(49.2)$ & $196(42.5)$ & $38(8.2)$ & 461 & 0.91 \\
\hline & Children & $204(49.3)$ & $179(43.2)$ & $31(7.5)$ & 414 & 0.67 \\
\hline \multirow[t]{3}{*}{ rs 12507396} & Control & $884(81.3)$ & $192(17.7)$ & $11(1)$ & 1087 & \\
\hline & Adults & $423(81.2)$ & $92(17.7)$ & $6(1.1)$ & 521 & 0.97 \\
\hline & Children & $373(80)$ & $86(18.5)$ & $7(1.5)$ & 466 & 0.65 \\
\hline \multirow[t]{3}{*}{ rs6857530 } & Control & $398(36.7)$ & $515(47.5)$ & $171(15.7)$ & 1,084 & \\
\hline & Adults & $173(34.5)$ & $242(48.3)$ & $86(17.2)$ & 501 & 0.64 \\
\hline & Children & $174(35.3)$ & $236(47.8)$ & $83(16.8)$ & 493 & 0.81 \\
\hline \multirow[t]{3}{*}{ rs6857715 } & Control & $475(50.6)$ & $378(40.3)$ & $85(9.1)$ & 938 & \\
\hline & Adults & $204(42.6)$ & $208(43.4)$ & $67(14)$ & 479 & 0.002 \\
\hline & Children & $192(42.8)$ & $213(47.4)$ & $44(9.8)$ & 449 & $0.02^{\mathrm{a}}$ \\
\hline \multirow[t]{3}{*}{ rs2234759 } & Control & $514(66.4)$ & 221 (28.6) & $39(5.0)$ & 774 & \\
\hline & Adults & $350(67.7)$ & $146(28.2)$ & $21(4.1)$ & 517 & 0.7 \\
\hline & Children & $255(66.7)$ & $115(30.1)$ & $12(3.1)$ & 382 & 0.31 \\
\hline \multirow[t]{3}{*}{ rs 1047214} & Control & $313(30)$ & 506 (48.) & $223(21.4)$ & 1,042 & \\
\hline & Adults & $143(28.9)$ & $255(51.5)$ & 97 (19.6) & 495 & 0.53 \\
\hline & Children & 137 (29.9) & $233(50.9)$ & 88 (19.2) & 458 & 0.58 \\
\hline
\end{tabular}

Analysis of the SNPs is based on a co-dominant model

${ }^{a}$ This result does not remain significant after multiple testing is taken into account

The association for NPY2R SNP rs6857715 in severely obese adults remains significant even after correction

For $N P Y 2 R$ SNPs the experiment-wide significance threshold required to keep type I error rate at $5 \%$ is 0.008

Male and female (sex-separated) analysis can be found in the (ESM Tables 3 and 4, respectively)

(chr4:156486787) in humans was tested for alignment in other species (dog, zebra fish, chicken, frog, fugu, rat, mouse and cow). It was found that the SNP was conserved as a ' $\mathrm{C}$ ' nucleotide only in the cow.

No known transcription factor binding sites could be identified using either Genomatix (http://www.bfam.bio. wzw.tum.de/partners/genomatix) or Tess (http://www.cbil. upenn.edu/tess) that overlapped with rs6857715. A possible explanation for this association could be that this variant is in LD with the true functional variant. In our results the rs6857715 was in LD with the following SNPs: rs $17376798 \quad\left(D^{\prime}=0.833\right)$, G-6503A $\left(D^{\prime}=0.859\right)$, rs12507396 $\left(D^{\prime}=0.974\right), \operatorname{rs} 6857530\left(D^{\prime}=0.994\right)$ and rs2234759 $\left(D^{\prime}=0.946\right)$. However, these SNPs were not

Table 4 Association studies of SNP rs1047214 in the NPY2R gene with BMI and WHR

\begin{tabular}{|c|c|c|c|c|c|c|}
\hline \multirow[t]{2}{*}{ Subjects } & \multirow[t]{2}{*}{ Traits } & \multicolumn{3}{|l|}{ Genotypes } & \multicolumn{2}{|l|}{$p$ values } \\
\hline & & $\mathrm{T} / \mathrm{T}$ & $\mathrm{T} / \mathrm{C}$ & $\mathrm{C} / \mathrm{C}$ & Co-dominant model & Recessive model \\
\hline \multirow[t]{3}{*}{ All obese children } & $n$ & 171 & 280 & 116 & & \\
\hline & BMI $\left(\mathrm{kg} / \mathrm{m}^{2}\right)$ & $29.1 \pm 6.3$ & $29.1 \pm 6.4$ & $28.5 \pm 6.0$ & 0.688 & 0.387 \\
\hline & WHR & $0.917 \pm 0.08$ & $0.916 \pm 0.07$ & $0.948 \pm 0.09$ & $0.005^{\mathrm{a}}$ & $0.001^{\mathrm{a}}$ \\
\hline \multirow[t]{3}{*}{ Male obese children } & $n$ & 87 & 130 & 62 & & \\
\hline & BMI $\left(\mathrm{kg} / \mathrm{m}^{2}\right)$ & $29.1 \pm 5.8$ & $28.9 \pm 6.7$ & $27.6 \pm 4.5$ & 0.317 & 0.141 \\
\hline & WHR & $0.94 \pm 0.09$ & $0.95 \pm 0.07$ & $0.98 \pm 0.10$ & 0.038 & 0.01 \\
\hline \multirow[t]{3}{*}{ Female obese children } & $n$ & 84 & 150 & 54 & & \\
\hline & BMI $\left(\mathrm{kg} / \mathrm{m}^{2}\right)$ & $29.1 \pm 6.8$ & $29.2 \pm 6.2$ & $29.6 \pm 7.4$ & 0.922 & 0.793 \\
\hline & WHR & $0.89 \pm 0.07$ & $0.89 \pm 0.07$ & $0.91 \pm 0.07$ & 0.084 & 0.05 \\
\hline
\end{tabular}

All results are means $\pm \mathrm{SD}$. Co-dominant model is TT vs TC vs CC and recessive model is TT $+\mathrm{TC}$ vs CC, $n$ is the total number of subjects with each particular genotype

${ }^{\mathrm{a}}$ These results remain significant after correction for multiple testing 
Fig. 3 Co-segregation of rare $N P Y 2 R$ variant $\mathrm{C}-5641 \mathrm{~T}$ in an obesity-enriched pedigree. Circles, female subjects; boxes, male subjects; black boxes or black circles, affected individuals within the pedigree; empty circles or empty boxes, unaffected individuals

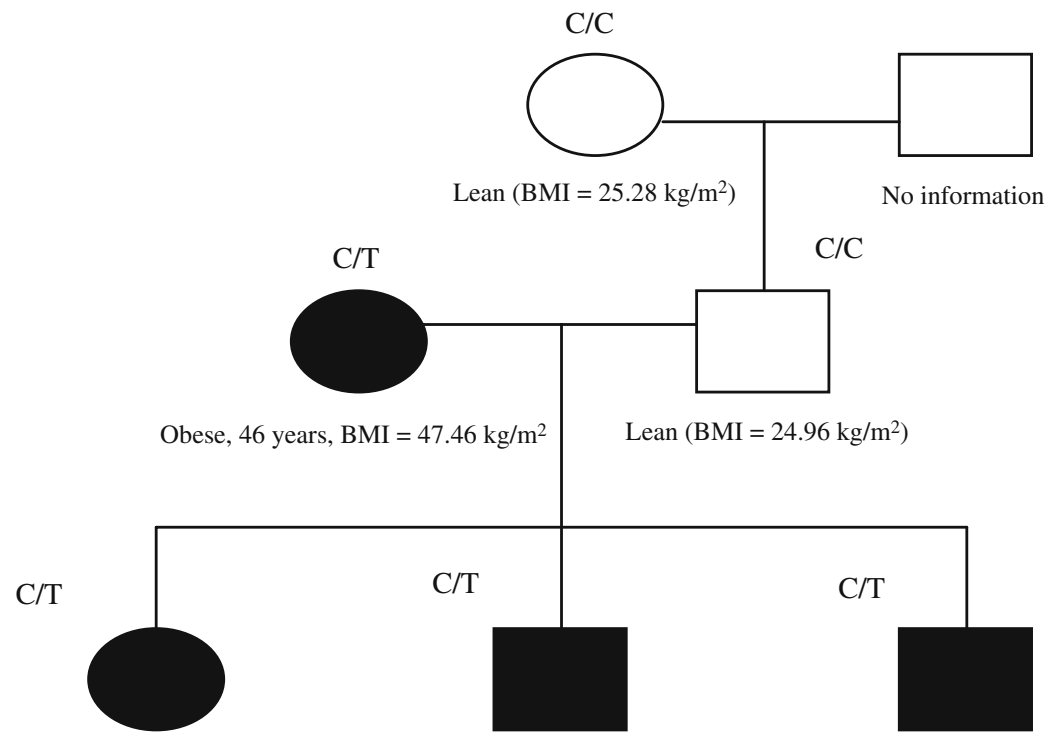

Obese, 15 years, $z$ score of BMI $=2.91 \quad$ Obese, 21 years, $z$ score of BMI $=2.40$ Obese, 11 years, $z$ score of BMI $=3.30$ associated with obesity and this is probably due to differences in allele frequencies.

Unlike the previous three studies, there was no association of the NPY2R rs1047214 variant with obesity when considering all subjects and even when separating based on sex $(p>0.05)$. When analysing the quantitative traits of BMI and WHR for all the SNPs, it was observed that there was a significant association with SNP rs1047214 and an increase in WHR in severely obese children $(p=0.005)$; this was more evident in the male children compared with the females. A significant association was also observed for rs1047214 variant with an increase in weight at age 20 for the morbidly obese adult males. Thus our results support the fact that this SNP may be important in determining BMI and WHR especially in young males. However, there was no significant association detected in the case-control analysis for rs1047214 and this could be due to the fact that subjects were selected based on BMI and not WHR. We were unable to demonstrate the previously described association of rs1047214 SNP with fasting NEFA due to our study design not including this quantitative measurement.

The difference in results for the qualitative analysis of adult obesity and association with NPY2R rs1047214 variant could be due to a number of reasons. One reason may be the differences in the number of individuals between ours and the Pima Indian study. In the Pima Indians male-only analysis the total number of subjects was only 167 (100 obese and 67 lean subjects). In the Swedish subjects there were a total of 148 lean, 129 overweight and 226 morbidly obese males. In the current study there were 648 male subjects (131 obese and 517 lean subjects). The second reason could be the difference in ethnic origin of the subjects.
There was no association with the quantitative measures of BMI and WHR for the three obesity associated SNPS (PYY rs162430 and NPY2R rs6857715 and rs2234759), while these were found to be associated with obesity in the case-control analysis. This could be due to the fact that obesity is not just purely defined by BMI and WHR but it is a complex entity and it could be due to an influence of the variant on other obesity traits, such as feeding behaviour, for which we did not have adequate numbers for analysis.

Rare variants were also studied, and one $N P Y 2 R$ variant, C-5641T, was not found in the lean controls $(n=1,163)$. In 700 obese children from 479 distinct pedigrees it was found to co-segregate with obesity in one family and may play a potential role in predisposition to monogenic obesity. This variant is not conserved in other species (data not shown); however, in order to establish the possible functional role of this variant, the sequence containing the $N P Y 2 R$ rare variant was analysed using Genomatix and the T allele introduces a transcriptional factor binding site for steroidogenic factor-1, which is a member of the nuclear hormone receptor family of transcriptional regulators and acts at multiple levels of the hypothalamic-pituitary-steroidogenic organ axis to regulate the expression of genes that are important for regulated steroidogenesis. The exact mechanism of how this may influence obesity is unclear. It is necessary to study additional pedigrees carrying the C-5641T mutation to confirm its implication in monogenic forms of obesity. We did not study the previously associated $P Y Y$ rare variant (Q62P) [40] as this was not found by sequencing in our subjects $(n=161)$.

There was only marginal association to one PYY SNP (rs162430). This intron 3 SNP was found to be significantly associated $(p=0.04)$ with childhood obesity but not adult 
obesity. The rare $\mathrm{T}$ allele was more prevalent in the obese children $(13 \%)$ compared with the control subjects $(10 \%)$ $(\mathrm{OR}=1.32$ [95\% CI 1.04-1.67], $p=0.03)$. However, these results are not significant if corrected for multiple testing. This variant was also found to be significantly associated $(p=0.001)$ in Pima Indian men with severe obesity [35]. However, we found no significant association when restricting the analysis to male subjects $(p>0.05)$. A possible explanation of the stronger association could be high LD with two novel $5^{\prime}$ variants identified in the Pima Indians, which were not tested in our population as they were upstream of the 1-kb region covered in our study.

In summary, significant association was observed for a $5^{\prime}$ flanking variant (rs6857715) of the NPY2R gene with both childhood and adult obesity in French white subjects. There was also a significant association with an increase in WHR in severely obese children and rs 1047214 variant of the $N P Y 2 R$ gene. One rare $N P Y 2 R$ variant (C-5641T) was found to co-segregate with obesity in one family, but further work is necessary in other pedigrees to confirm these results. Association was also observed for the PYY variant rs162430 with childhood obesity; however, this becomes non-significant if multiple testing correction is applied. Lastly no association was observed for variants in the $10-\mathrm{kb}$ interval between PYY and PPY. To the best of our knowledge, this is the first study that has examined the genetic variants in the $P P Y$ gene in relation to obesity, in both morbidly obese adults and children. So far there is a great deal of evidence for a crucial role of the $P P Y$ gene in obesity, and it is important to examine the hypothesis that genetic variants could be responsible for variable levels of expression of PPY in obese subjects. However, our study, which was purely genetic, shows that variants in the $P P Y$ gene are not associated with severe obesity.

In conclusion, our work builds upon the previous studies and suggests that on a genetic level specific variants in the $N P Y 2 R$ gene are associated with obesity and further work is necessary to understand the physiology of the receptor.

Acknowledgements This work was funded by the Medical Research Council (G0000477). We would like to thank C. Lecoeur (Pasteur Institute, Lille, France) for her help in the selection of subjects for the initial sequencing work. We would also like to thank M. Benzinou (Imperial College, London) for his help in using UNPHASED and S. Gallina (Pasteur Institute, Lille, France) for her help with Genomatix Software.

Duality of interest The authors would like to confirm that there are no conflicts of interest associated with this study.

\section{References}

1. Korner J, Leibel RL (2003) To eat or not to eat-how the gut talks to the brain. N Engl J Med 349:926-928
2. Erlanson-Albertsson C (2005) How palatable food disrupts appetite regulation. Basic Clin Pharmacol Toxicol 97:61-73

3. Ramos EJ, Meguid MM, Campos AC, Coelho JC (2005) Neuropeptide Y, alpha-melanocyte-stimulating hormone, and monoamines in food intake regulation. Nutrition 21:269-279

4. Horvath TL (2005) The hardship of obesity: a soft-wired hypothalamus. Nat Neurosci 8:561-565

5. Adrian TE, Ferri GL, Bacarese-Hamilton AJ, Fuessl HS, Polak JM, Bloom SR (1985) Human distribution and release of a putative new gut hormone, peptide YY. Gastroenterology 89:1070-1077

6. Batterham RL, Cowley MA, Small CJ et al (2002) Gut hormone PYY(3-36) physiologically inhibits food intake. Nature 418:650 654

7. Ekblad E, Sundler F (2002) Distribution of pancreatic polypeptide and peptide YY. Peptides 23:251-261

8. Hort Y, Baker E, Sutherland GR, Shine J, Herzog H (1995) Gene duplication of the human peptide YY gene (PYY) generated the pancreatic polypeptide gene (PPY) on chromosome 17q21.1. Genomics 26:77-83

9. Grandt D, Teyssen S, Schimiczek M et al (1992) Novel generation of hormone receptor specificity by amino terminal processing of peptide YY. Biochem Biophys Res Commun 186:1299-1306

10. Grandt D, Schimiczek M, Beglinger C et al (1994) Two molecular forms of peptide YY (PYY) are abundant in human blood: characterization of a radioimmunoassay recognizing PYY 1-36 and PYY 3-36. Regul Pept 51:151-159

11. Grandt D, Schimiczek M, Struk K et al (1994) Characterization of two forms of peptide YY, PYY(1-36) and PYY(3-36), in the rabbit. Peptides 15:815-820

12. Batterham RL, Cohen MA, Ellis SM et al (2003) Inhibition of food intake in obese subjects by peptide YY3-36. N Engl J Med 349:941-948

13. Pittner RA, Moore CX, Bhavsar SP et al (2004) Effects of PYY [3-36] in rodent models of diabetes and obesity. Int J Obes Relat Metab Disord 28:963-971

14. Vrang N, Madsen AN, Tang-Christensen M, Hansen G, Larsen PJ (2006) PYY(3-36) reduces food intake and body weight and improves insulin sensitivity in rodent models of diet-induced obesity. Am J Physiol Regul Integr Comp Physiol 291:R367R375

15. Adams SH, Lei C, Jodka CM et al (2006) PYY[3-36] administration decreases the respiratory quotient and reduces adiposity in diet-induced obese mice. J Nutr 136:195-201

16. Chelikani PK, Haver AC, Reidelberger RD (2005) Intravenous infusion of peptide YY(3-36) potently inhibits food intake in rats. Endocrinology 146:879-888

17. Boey D, Lin S, Karl T et al (2006) Peptide YY ablation in mice leads to the development of hyperinsulinaemia and obesity. Diabetologia 49:1360-1370

18. Moran TH, Smedh U, Kinzig KP, Scott KA, Knipp S, Ladenheim EE (2005) Peptide YY(3-36) inhibits gastric emptying and produces acute reductions in food intake in rhesus monkeys. Am J Physiol Regul Integr Comp Physiol 288:R384-R388

19. le Roux CW, Batterham RL, Aylwin SJ et al (2006) Attenuated peptide YY release in obese subjects is associated with reduced satiety. Endocrinology 147:3-8

20. Doggrell SA (2004) Can food intake be reduced with peptide YY3-36? Expert Opin Investig Drugs 13:285-287

21. Degen L, Oesch S, Casanova M et al (2005) Effect of peptide YY336 on food intake in humans. Gastroenterology 129:1430-1436

22. Tschop M, Castaneda TR, Joost HG et al (2004) Physiology: does gut hormone PYY3-36 decrease food intake in rodents? Nature 430:1 p following 165; discussion $2 \mathrm{p}$ following 165

23. Boggiano MM, Chandler PC, Oswald KD et al (2005) PYY3-36 as an anti-obesity drug target. Obes Rev 6:307-322 
24. Broberger C, Landry M, Wong H, Walsh JN, Hokfelt T (1997) Subtypes $\mathrm{Y} 1$ and $\mathrm{Y} 2$ of the neuropeptide $\mathrm{Y}$ receptor are respectively expressed in pro-opiomelanocortin- and neuropeptide-Y-containing neurons of the rat hypothalamic arcuate nucleus. Neuroendocrinology 66:393-408

25. Naveilhan P, Hassani H, Canals JM et al (1999) Normal feeding behavior, body weight and leptin response require the neuropeptide Y Y2 receptor. Nat Med 5:1188-1193

26. Perusse L, Rice T, Chagnon YC et al (2001) A genome-wide scan for abdominal fat assessed by computed tomography in the Quebec Family Study. Diabetes 50:614-621

27. Marco J, Zulueta MA, Correas I, Villanueva ML (1980) Reduced pancreatic polypeptide secretion in obese subjects. J Clin Endocrinol Metab 50:744-747

28. Lassmann V, Vague P, Vialettes B, Simon MC (1980) Low plasma levels of pancreatic polypeptide in obesity. Diabetes 29:428-430

29. Uhe AM, Szmukler GI, Collier GR, Hansky J, O'Dea K, Young GP (1992) Potential regulators of feeding behavior in anorexia nervosa. Am J Clin Nutr 55:28-32

30. Asakawa A, Inui A, Yuzuriha $\mathrm{H}$ et al (2003) Characterization of the effects of pancreatic polypeptide in the regulation of energy balance. Gastroenterology 124:1325-1336

31. Zipf WB, O’Dorisio TM, Cataland S, Sotos J (1981) Blunted pancreatic polypeptide responses in children with obesity of Prader-Willi syndrome. J Clin Endocrinol Metab 52:1264-1266

32. Asakawa A, Inui A, Ueno N, Fujimiya M, Fujino MA, Kasuga M (1999) Mouse pancreatic polypeptide modulates food intake, while not influencing anxiety in mice. Peptides 20:1445-1448

33. Batterham RL, Le Roux CW, Cohen MA et al (2003) Pancreatic polypeptide reduces appetite and food intake in humans. J Clin Endocrinol Metab 88:3989-3992

34. Reinehr T, Enriori PJ, Harz K, Cowley MA, Roth CL (2006) Pancreatic polypeptide in obese children before and after weight loss. Int J Obes (Lond) 30:1476-1481

35. Ma L, Tataranni PA, Hanson RL et al (2005) Variations in peptide YY and Y2 receptor genes are associated with severe obesity in Pima Indian men. Diabetes 54:1598-1602

36. Hung CC, Pirie F, Luan J et al (2004) Studies of the peptide YY and neuropeptide $\mathrm{Y} 2$ receptor genes in relation to human obesity and obesity-related traits. Diabetes 53:2461-2466

37. Lavebratt C, Alpman A, Persson B, Arner P, Hoffstedt J (2006) Common neuropeptide $\mathrm{Y} 2$ receptor gene variant is protective against obesity among Swedish men. Int J Obes (Lond) 30:453-459
38. Barroso I, Luan J, Middelberg RP et al (2003) Candidate gene association study in type 2 diabetes indicates a role for genes involved in beta-cell function as well as insulin action. PLoS Biol 1:E20

39. Torekov SS, Larsen LH, Glumer C et al (2005) Evidence of an association between the Arg72 allele of the peptide YY and increased risk of type 2 diabetes. Diabetes 54:2261-2265

40. Ahituv N, Kavaslar N, Schackwitz W et al (2006) A PYY Q62P variant linked to human obesity. Hum Mol Genet 15:387-391

41. Poskitt EM (1995) Defining childhood obesity: the relative body mass index (BMI). European Childhood Obesity group. Acta Paediatr 84:961-963

42. Bell CG, Meyre D, Samson C et al (2005) Association of melaninconcentrating hormone receptor $15^{\prime}$ polymorphism with earlyonset extreme obesity. Diabetes 54:3049-3055

43. Rozen S (2000) Primer3 on the WWW for general users and for biologist programmers. Humana, Totowa, NJ

44. Bell CG, Meyre D, Samson C et al (2005) Association of melaninconcentrating hormone receptor $15^{\prime}$ polymorphism with earlyonset extreme obesity. Diabetes 54:3049-3055

45. Jurinke C, van den Boom D, Cantor CR, Koster H (2002) Automated genotyping using the DNA MassArray technology. Methods Mol Biol 187:179-192

46. Abecasis GR, Cookson WO (2000) GOLD - graphical overview of linkage disequilibrium. Bioinformatics 16:182-183

47. Dudbridge F (2003) Pedigree disequilibrium tests for multilocus haplotypes. Genet Epidemiol 25:115-121

48. Nyholt DR (2004) A simple correction for multiple testing for single-nucleotide polymorphisms in linkage disequilibrium with each other. Am J Hum Genet 74:765-769

49. Purcell S, Cherny SS, Sham PC (2003) Genetic Power Calculator: design of linkage and association genetic mapping studies of complex traits. Bioinformatics 19:149-150

50. Sainsbury A, Schwarzer C, Couzens M et al (2002) Important role of hypothalamic Y2 receptors in body weight regulation revealed in conditional knockout mice. Proc Natl Acad Sci USA 99:89388943

51. Abbott CR, Small CJ, Kennedy AR et al (2005) Blockade of the neuropeptide Y Y2 receptor with the specific antagonist BIIE0246 attenuates the effect of endogenous and exogenous peptide YY (3-36) on food intake. Brain Res 1043:139-144

52. Renshaw D, Batterham RL (2005) Peptide YY: a potential therapy for obesity. Curr Drug Targets 6:171-179 